\title{
Positive effect of dietary lutein and cholesterol on the undirected song activity of an opportunistic breeder
}

\author{
Stefania Casagrande ${ }^{\text {Corresp., }}{ }^{1,2}$, Rianne Pinxten ${ }^{2,3}$, Erika Zaid ${ }^{2,4}$, Marcel Eens ${ }^{2}$ \\ ${ }^{1}$ Evolutionary Physiology Group, Max Planck Institute for Ornithology, Seewiesen, Germany \\ 2 Department of Biology, Behavioural Ecology and Ecophysiology Group, University of Antwerp, Antwerp, Belgium \\ 3 Faculty of Social Sciences, Antwerp School of Education, University of Antwerp, Antwerp, Belgium \\ 4 Department of Zoology, School of Life Sciences, La Trobe University, Melbourne, Victoria, Australia \\ Corresponding Author: Stefania Casagrande \\ Email address: scasagrande@orn.mpg.de
}

Song is a sexually selected trait that is thought to be an honest signal of the health condition of an individual in many bird species. For species that breed opportunistically, the quantity of food may be a determinant of singing activity. However, it is not yet known whether the quality of food plays an important role in this respect. The aim of the present study was to experimentally investigate the role of two calorie-free nutrients (lutein and cholesterol) in determining the expression of a sexually selected behavior (song rate) and other behaviors (locomotor activity, self-maintenance activity, eating and resting) in male zebra finches (Taeniopygia guttata). We predicted that males supplemented with lutein and cholesterol would sing at higher rates than controls because both lutein and cholesterol have important health-related physiological functions in birds and birdsong mirrors individual condition. To control for testosterone secretion that may upregulate birdsong, birds were exposed to a decreasing photoperiod. Our results showed that control males down-regulated testosterone in response to a decreasing photoperiod, while birds treated with lutein or cholesterol maintained a constant singing activity. Both lutein- and cholesterol-supplemented groups sang more than control groups by the end of the experiment, indicating that the quality of food can affect undirected song irrespective of circulating testosterone concentrations. None of the other measured behaviors were affected by the treatment, suggesting that, when individuals have full availability of food, sexually selected song traits are more sensitive to the effect of food quality than other behavioral traits. Overall the results support our prediction that undirected song produced by male zebra finches signals access to high-quality food. 
1 Positive effect of dietary lutein and cholesterol on the undirected song activity

2

3

4

5

6

7

\title{
of an opportunistic breeder
}

\author{
Stefania Casagrande ${ }^{1,2}$ Rianne Pinxten $^{2,3}$, Erika Zaid ${ }^{2,4}$, Marcel Eens ${ }^{2}$
}

${ }^{1}$ Max Planck Institute for Ornithology, Evolutionary Physiology Group, Eberhard-Gwinner-Str. Haus 5, 82319 Seewiesen - Germany

2 Department of Biology, Behavioural Ecology and Ecophysiology group, University of Antwerp, Campus Drie Eiken, Universiteitsplein 1 - 2610 Wilrijk, Antwerp, Belgium

${ }^{3}$ Faculty of Social Sciences, Antwerp School of Education, University of Antwerp, Venusstraat 35, Antwerp, Belgium

${ }^{4}$ Department of Zoology, School of Life Sciences, La Trobe University, Melbourne, Victoria, Australia

* Corresponding author. E-mail address: scasagrande@orn.mpg.de; Phone: +49 8157932248

\section{Abstract}

Song is a sexually selected trait that is thought to be an honest signal of the health condition of an individual in many bird species. For species that breed opportunistically, the quantity of food may be a determinant of singing activity. However, it is not yet known whether the quality of food plays an important role in this respect. The aim of the present study was to experimentally investigate the role of two calorie-free nutrients (lutein and cholesterol) in determining the duration of undirected song (type of song not directed toward a female) singing activity and other behaviors (locomotor activity, self-maintenance activity, eating and resting) in male zebra finches (Taeniopygia guttata). We predicted that males supplemented with lutein and cholesterol would sing at higher rates than controls because both lutein and cholesterol have important health-related physiological functions in birds and birdsong can mirror individual condition. To control for testosterone ( $\mathrm{T}$ ) secretion that may upregulate birdsong, birds were exposed to a decreasing photoperiod. Our results showed that control males down-regulated singing activity in response to a decreasing photoperiod, while birds treated with lutein or cholesterol maintained a constant singing activity. Both lutein- and cholesterol-supplemented groups sang more than 
32 control groups by the end of the experiment, indicating that the quality of food can affect

33 undirected song irrespective of circulating $\mathrm{T}$ concentrations. None of the other measured

34 behaviors were affected by the treatment, suggesting that, when individuals have full availability

35 of food, sexually selected song traits are more sensitive to the effect of food quality than other

36 behavioral traits. Overall the results support our prediction that undirected song produced by

37 male zebra finches signals access to high-quality food.

38 
40

41

42

43

44

45

\section{Introduction}

Individuals of different species have evolved a wide array of traits to signal their condition to perspective potential mates or rivals (von Schantz et al. 1999; Johnstone et al. 2009; Hill 2011).

The communicative potential of songbirds relies, in large part, on the production of complex and prolonged songs that are evaluated by conspecifics to assess the "quality" (sensu Wilson and Nussey, 2010) of the emitter (Duffy and Ball, 2002; Garamszegi et al., 2003; Møller et al., 2000;

Nowicki and Searcy, 2004; Tregenza et al., 2006). Song can be an expression of quality because its production is a finely-tuned process easily limited by several factors (reviewed in Gil and Gahr, 2002). Although the matter is still debated (e.g. Ophir et al., 2010; Ward, 2004), the existence of direct costs sustained by the increase of oxygen consumption associated with singing activity, suggests that it is an energetically demanding task (Franz and Goller 2003; Hasselquist and Bensch, 2008; Zollinger et al., 2011; but see Ward 2004), which must be tradedoff with other activities. For example, it has been observed that birdsong decreases along with lowering temperatures, probably resulting from an increased need to maintain thermostasis (Dunn and Zann, 1996). Even more convincing is the evidence from the link between food availability and singing. For example, male pied flycatchers (Ficedula hypoleuca) provided with supplemental food sang more and had more complex songs than controls (Lampe and Espmark, 2002). Similarly, dunnock males (Prunella modularis) supplemented with additional food sang at higher rates than control males (Davies and Lundberg, 1984). Other species, such as the European starling (Sturnus vulgaris) sing at higher rates when they have a better nutritional status as suggested by high levels of cholesterol and albumin in the plasma (Van Hout et al., 2012). The association between the nutritional state of singing birds and their song performance can be explained by the activation of the metabolic pathways that are needed to exhibit an energy demanding activity such as singing (Hasselquist and Bensch, 2008). On the other side, food shortage can have a negative impact on birdsong. In the zebra finch (Taeniopygia guttata), Lynn et al. (2010) found a reduction in the expression of undirected song and courtship behavior following 4 hours of fasting. Similarly, Ritschard and Brumm (2012) found that zebra finches kept under food restriction performed a lower rate of undirected song than controls. Another study reported that this relationship was mediated by male condition (indicated by body mass; Geberzahn and Gahr, 2011). Despite the existence of a clear association between the nutritional 
state and song performance, studies on how food quality can affect song remain very rare (but see Casagrande et al., 2015, 2014; Van Hout et al., 2011).

In general, males of almost all songbird species produce song in response to the presence of a conspecific with the intent of attracting it (courtship) or repelling it (agonistic interactions), or more generally, to induce a modification in the behavior of the listener (Riters, 2011). In zebra finches this type of song is named "directed song", which is usually regulated by sex steroids (Catchpole and Slater, 2008) and produced in contexts related to reproduction (Riebel 2009). In addition to directed song, zebra finches also sing an "undirected song", which is not directed at a particular individual. Directed and undirected songs also differ bioacoustically in the rate of syllable delivery, stereotypy and number of introductory elements (Riebel, 2009), as well as in their neural, genetic and endocrinological control (Jarvis et al. 1998). Although sexual selection probably acts less intensely on undirected song compared to directed song, it can be considered a sexually selected trait because it can enhance the chance of mating by attracting a mate when the female of the social pair is not present, gaining a higher chance of re-mating in case of partner loss, maintaining pair bonds and increasing the frequency of extra-pair copulations (Dunn and Zann, 1996, 1997). Laboratory experiments show that undirected song is indeed attractive to female zebra finches (Holveck and Riebel, 2007; Jesse and Riebel, 2012; Tomaszycki and Adkins-Regan, 2005). Studies carried out in free-living zebra finches (Taeniopygia guttata) revealed that undirected song is performed at high levels throughout the year and that it is more frequent than directed song with clear signaling functions even related to sexual behavior (Dunn and Zann, 1996). For example, higher rates of undirected song performed near the nest correlate with the presence of the females in the nest, suggesting a within-pair function of undirected song (Dunn and Zann, 1996). Even though undirected song can also be produced independently of sex steroids (Pröve, 1974) or an active reproductive state (Perfito et al., 2008), it can respond to androgens similarly to directed song (Pröve and Immelmann, 1982; Walters et al., 1991), but may have a much lower threshold for hormonal activation (Pröve 1974).

It has now been repeatedly shown that dietary lutein, which is a calorie-free micronutrient, promotes the undirected song duration of male European starlings (Casagrande et al., 2014; Van Hout et al., 2011), even in males that were coping with an inflammatory response (Casagrande et al. 2015). Lutein is a hydroxy-carotenoid synthetized by autotrophic organisms that, besides acting as a pigment and as an enhancer of the immune system (Svensson and Wong, 
101 2011), is known mostly for its antioxidant properties (Hill and Johnson, 2012; Vinkler and 102 Albrecht, 2010; Pérez-Rodríguez, 2009; Casagrande et al., 2014). As with all carotenoids, lutein

103

104

105

106

107

108

109

110

111

112

113

114

115

116

117

118

119

120

121

122

123

124

125

126

127

128

129

130

131

cannot be synthetized by animals and thus represents a potentially limited resource obtained only by eating lutein-rich food. Consequently, it is generally expected that, since lutein is a limited resource with beneficial effects on the oxidative status, and since birdsong can mirror oxidative condition (Casagrande et al. 2016), birds with access to lutein-rich food can potentially improve their singing performance and, consequently, fitness outcome.

Another multi-functional molecule that can be acquired through the diet, but that also can be synthesized endogenously is cholesterol, a calorie-free sterol which is known to determine the structure and functionality of the animal cells' membrane. It has also been demonstrated that within certain concentrations cholesterol has clear antioxidant functions that improve the health status of vertebrates (Brown and Galea, 2010; Casagrande et al., 2014; Murphy and Johnson, 2008; Smith, 1991). Recently, a relationship has also been reported between cholesterol and the expression of song in European starlings, where circulating cholesterol levels were positively associated with song rate (Van Hout et al. 2012).

The general aim of the present study was to experimentally investigate the effect of these calorie-free micronutrients on the duration of undirected song. Specifically, our study aimed at determining whether a potentially ecologically relevant cue such as food quality can affect undirected singing behavior.

We addressed this question in the zebra finch, a granivorous, non-territorial and colonial species adapted to breed opportunistically (Zann, 1996), but that in more temperate regions of its range (Australia and Indonesia) is more sensitive to photoperiodic fluctuations (Zann, 1996; Zann et al., 1995). This opportunistic species has evolved in unpredictable environments and is highly responsive to local non-seasonal conditions such as water and food availability (Perfito et al., 2006, 2008; Prior and Soma, 2015). It has also been recently discovered that the structure of the neural song system shows a seasonal-like variation that may be related to the reproductive state (testis volume), although investigations of the relationship between song nuclei and circulating sex steroids are still missing (Perfito et al., 2015).

Birds were kept under a dynamically decreasing photoperiod, as sex steroids are predicted to decrease with the shortening of daylight also in this opportunistic species (Bentley et al., 2000; Perfito et al., 2008). We determined the hormonal profile of individuals by measuring 
132 circulating testosterone. Since this hormone can regulate a wide array of behavioral patterns

133 related to the breeding state, and since sexually selected and naturally selected traits can have 134 different sensitivity to both hormones and micronutrients (Cotton et al., 2004; Johnstone et al., 135 2009; Van Hout et al., 2011), we recorded the effect of our treatments on singing behavior, as 136 well as on other observed behaviors (see below). We expected that: 1. Birds would decrease 137 undirected song when T concentrations decrease when kept on a standard diet; 2. Lutein and 138 cholesterol would positively affect singing activity, but not other behaviors, because the positive 139 effect of micronutrients will be more pronounced on a sexual trait such as undirected song.

\section{Materials \& Methods}

142 Experimental design and food manipulation

143 The study was approved by the ethical committee for animal experiments (ECD) of the University of Antwerp (ID number: 2014-21). Forty-three adult zebra finch males of similar age were acquired from a local authorized pet shop with certified origin. Birds were allowed to acclimatize for three weeks before the onset of the experiment. Each male was housed in an individual cage ( $\mathrm{L}$ x W x H: $60 \times 25 \times 35 \mathrm{~cm}$ ) equipped with 3 perches, birds' grit and ad libitum access to food, water and cuttlefish bone. Extra water for bathing was offered on a weekly basis to allow the birds to accomplish natural self-maintenance activities. The cages were adjacent to each other, arranged against two opposite walls of an animal-approved indoor room at the campus Drie Eiken of the University of Antwerp, where birds (only males were present in the room) were in constant visual and auditory contact with each other. Males of different treatments were randomly positioned in one of the 43 cages in order to avoid any bias imputable to the location of the cage. Birds were exposed to constant temperature (about $20{ }^{\circ} \mathrm{C}$ ) and short decreasing photoperiod resembling the photoperiod variation observed in Antwerp during the course of the experiment (variation in duration of daylight between 6 November - 6 December 2012: $9 \mathrm{~h} 22 \mathrm{~m}-8 \mathrm{~h} 04 \mathrm{~m})$. The light was switched on and off by an automatic system and included a gradual change of light to mimic twilight that lasted 30 min after 'lights on' and 30 min before 'lights off'. The modification of the day length was performed manually daily by the researchers. All birds, irrespective of the treatment, were fed an ad libitum diet of water and a mix of seeds for finches containing about $2.75 \mu \mathrm{g}^{*} \mathrm{~g}^{-1}$ of lutein and zeaxanthin (respectively 10:1) 
163 about $3 \mathrm{~g}$ of seeds/day (Perfito et al. 2008), the baseline average amount of lutein intake was

164 estimated to be at least $8 \mu \mathrm{g} /$ day.

165 On day 0, three different groups were created (Controls, Caro-males and Chol-males) for

166 the four weeks of the experiment (see Fig. 1 for the timing of the experiment). Fourteen

167 randomly selected males (Caro-males) received an additional $15 \mu \mathrm{g}^{*} \mathrm{ml}^{-1}$ of lutein (ORO GLO

168 Kemin Industries Inc., Iowa, USA; extracted from marigolds Tagetes erecta) in drinking water

169 provided in an opaque dispenser to prevent photo-oxidation (Alonso-Alvarez et al., 2004; Blount

170 et al., 2003; McGraw and Ardia, 2003). Considering a daily average intake of $2 \mathrm{ml}$ of water per

171 zebra finch fed the baseline seed diet of the studied colony and of other colonies kept under the

172 same conditions (McGraw and Ardia, 2003), the daily dose of lutein assumed during the

173 experiment by each individual was $38 \mu \mathrm{g}$ /day, approximately five times the amount of lutein

174 eaten by the 14 controls birds (C birds). Other 15 males (Chol-males) were fed seeds enriched

175 with 2\% powdered cholesterol (Sigma-Aldrich - Product code: 14606-100G-F) following the

176 protocol described by previous studies in the same species (Allen and Wong, 1993; McGraw and

177 Parker, 2006). Seeds provided to $\mathrm{C}$ and Caro birds were cholesterol free. Based on a previous

178 study, it is known that the provided concentration nearly doubles blood cholesterol levels in

179 zebra finches over the course of 3-4 weeks (McGraw and Parker, 2006).

180

181

Behavioral observations and analysis of recordings

182 We video-recorded the behavior of birds for 4 hours starting one hour after morning twilight, one

183 to three days before each sampling day (day 0, day 15 and day 30, respectively; see also Fig.1).

184 In total 14 to 15 birds were simultaneously recorded each day, assuring a balanced representation

185 of the 3 treatments. The recordings were subsequently analyzed in random order by a single

186 person (EZ) using a software for the analysis of behavioral data (The Observer XT, Noldus

187 Information Technologies, Wageningen, The Netherlands). In order to obtain an accurate

188 measure of all behaviors, even the ones that lasted for a very short time, the software was set to

189 automatically determine the duration of each behavior (event recorder) while the observer was

190 watching the video and hearing the sound. All activities of the focal bird were analyzed using a

191 segment of 20 minutes of recording, randomly chosen within the 4 hours of recording to avoid

192 any potential bias due to timing of activities. This amount of time was approximately twice the

193 duration that is usually used to assess activity levels in this species (Lopes et al., 2012). We 
194 discarded the first 30 minutes of recordings as during this period the behavior may still have

195 been potentially affected by the presence of the researchers that had installed the camera. The 196 activities were quantified as the total duration (in seconds) of resting (perching and standing on

197 the ground), self-maintenance activities (preening, scratching, and beak rubbing), locomotor 198 activity (hopping and flying), eating and singing undirected song, respectively. Although 199 directed and undirected songs are structurally very similar, undirected song is, by definition, not 200 directed toward a female and it is not associated with specific behavioral patterns related to the 201 breeding condition (Sossinka and Boehner, 1980).

202 On day 0 (start of treatment, first measure before food manipulation), day 15 and day 30

203 birds were weighed to the nearest gram to examine the effect of dietary treatments on the body 204 mass. Just before the measurement, males were blood sampled by venipuncturing the brachial 205 vein collecting $80 \mu \mathrm{L}$ of blood with heparinized microcapillary tubes. Plasma was removed from 206 centrifuged blood and stored at $-80^{\circ} \mathrm{C}$ in $1.5 \mathrm{~mL}$ Eppendorf tubes for $\mathrm{T}$ and lutein analyses (four 207 months later).

208

209

Hormonal assay

210 T concentrations were determined using enzyme immonoessay (EIA) kits (Cat. No. ADI-901211 065, Enzo Life Sciences, New York, USA) following a diethyl ether extraction of $25 \mu \mathrm{L}$ sample 212 volume. After drying the extract under N2 stream, $250 \mu \mathrm{L}$ of Assay Buffer was added (1:10 213 dilution), and the samples were allowed to reconstitute overnight at $4^{\circ} \mathrm{C}$. A stripped plasma 214 sample spiked with a known amount of $\mathrm{T}\left(2 \mathrm{ng}^{*} \mathrm{~mL}^{-1}\right)$ as well as one blank sample containing 215 only assay buffer were taken through the entire assay procedure. The next day, $100 \mu \mathrm{L}$ of each 216 sample (in duplicate) was added to individual wells on the assay plate alongside a standard curve 217 with 5 points ranging from $7.81 \mathrm{pg}$ to $2,000.00 \mathrm{pg}^{*} \mathrm{~mL}^{-1}$. The samples were distributed randomly 218 within and across plates but an individual's repeated samples were always included on the same 219 plate. The plate was read on a microplate reader (VersaMax, Molecular Devices Inc, California, 220 USA) at $405 \mathrm{~nm}$ with a correction wavelength set at $570 \mathrm{~nm}$. The average extraction efficiency 221 was $70 \%$ and final values were corrected accordingly. The average lower sensitivity of the 222 assays was at $3.25 \mathrm{pg}^{*} \mathrm{ml}^{-1}$. The mean intra-plate $\mathrm{CV}$ was $2.87 \%$, while the inter-plate $\mathrm{CV}$ were 223 calculated for three different concentrations of the standard curve and were, respectively, $4.73 \%$ 224 $\left(2,000 \mathrm{pg}^{*} \mathrm{ml}^{-1}\right), 0.7 \%\left(124 \mathrm{pg}^{*} \mathrm{ml}^{-1}\right)$ and $2.77 \%\left(7.8 \mathrm{pg}^{*} \mathrm{ml}^{-1}\right)$. 
Data analysis

227 We tested the effect of lutein and cholesterol supplementation on each recorded behavior, on circulating $\mathrm{T}$ and on body mass, by using a full factorial general linear mixed model. Treatment

229 (carotenoid treated -Caro; cholesterol treated - Chol; controls - C) and time (day 0, day 15 and day 30) were included as fixed factors, while a random intercept was specified for individual.

231

232

233

234

235

236

237

238

239

240

241

242

243

244

245

246

247 Significant differences between and within groups were ascertained by pairwise differences of least square means (Student's t-test) expressed by confidence intervals (reported in square brackets). After checking the normality of residuals and homogeneity of variance, only song duration (square root) and $\mathrm{T}(\log )$ were transformed, but original values are reported in Fig. 2. All statistical analyses were performed with SAS 9.3 (SAS Institute Inc. NC).

\section{Results}

\section{Singing activity}

There was a nearly significant interaction effect between treatment and time (time $\mathrm{x}$ treatment, $\mathrm{F}_{(4,80)}=2.32, \mathrm{p}=0.06$; treatment, $\mathrm{F}_{(2,80)}=1.64, \mathrm{p}=0.20$; time, $\left.\mathrm{F}_{(2,80)}=0.11, \mathrm{p}=0.89\right)$. Since singing activity can be affected by the quantity of food eaten, we controlled for this variable introducing eating behavior as covariate. The new model showed a significant time $\mathrm{x}$ treatment effect (time $\mathrm{x}$ treatment, $\mathrm{F}_{(4,80)}=2.64$, $\mathrm{p}=0.04$; treatment, $\mathrm{F}_{(2,80)}=2.22, \mathrm{p}=0.12$; time, $\left.\mathrm{F}_{(2,80)}=0.49, \mathrm{p}=0.62\right)$ and a significant effect of the total time spent eating behavior $\left(\mathrm{F}_{(1,119)}=9.54, \mathrm{p}=0.0025, \beta=-\right.$ $0.0079 \pm 0.003)$. Comparisons within groups showed that $\mathrm{C}$-males decreased their singing activity with time (day0-day30; -2.76 \pm 1.20 [-5.15,-0.36]; day15-day30: -2.66 $\pm 1.22[-5.08,-0.24]$ ), while this was not the case in Caro- and Chol-males (post-hoc results shown in Fig. 2a). Both Choland Caro-males sang significantly more than C-males during day 30 (Caro- vs. C-males: $4.60 \pm 1.49$ [-7.55,-1.64]; Chol- vs. C-males: $-3.46 \pm 1.46,[-6.36,-0.56])$, while on day 0 singing activity did no differ between the three treatment groups (Fig. 2a).

\section{Testosterone}

Circulating $\mathrm{T}$ concentrations decreased over time $\left(\mathrm{F}_{(2,80)}=28.80, \mathrm{p}<0.0001\right)$ in all groups independently from food treatments (time $\mathrm{x}$ treatment, $\mathrm{F}_{(4,80)}=0.34$, $\mathrm{p}=0.85$; treatment, 
$256 \mathrm{~F}_{(2,80)}=0.64, \mathrm{p}=0.53$; Fig $2 \mathrm{~b}$ ) reaching very low values on day 30 (about $200 \mu \mathrm{g} / \mathrm{ml}$ ). Males of the

257 three treatments did not differ in T levels on day 0.

258

259

Body mass

260 Treatment and time had no effect on body mass (time $\mathrm{x}$ treatment, $\mathrm{F}_{(4,80)}=0.28, \mathrm{p}=0.89$;

261 treatment, $\mathrm{F}_{(2,80)}=0.27, \mathrm{p}=0.77$; time, $\mathrm{F}_{(2,80)}=2.89$, $\mathrm{p}=0.06$ ) (Fig 2c). Body mass did not differ

262 among the 3 treatment groups before the start of the food supplementation

263 (all $\mathrm{p}>0.43$ ).

264

265

266

Other activities

267 The time spent eating did not vary between groups (time $\mathrm{x}$ treatment, $\mathrm{F}_{(4,80)}=0.75, \mathrm{p}=0.56$;

268 treatment, $\mathrm{F}_{(2,80)}=1.03, \mathrm{p}=0.36$; time, $\left.\mathrm{F}_{(2,80)}=2.12, \mathrm{p}=0.13\right)$, neither did the duration of resting

269 behavior (time, $\mathrm{F}_{(2,80)}=2.65, \mathrm{p}=0.08$, (time $\mathrm{x}$ treatment, $\mathrm{F}_{(4,80)}=0.66, \mathrm{p}=0.62$; treatment,

$\left.270 \mathrm{~F}_{(2,80)}=0.26, \mathrm{p}=0.77\right)$. Birds did not change their locomotor activity during the experiment (time $\mathrm{x}$

271 treatment, $\mathrm{F}_{(4,80)}=1.45, \mathrm{p}=0.23$; treatment, $\mathrm{F}_{(2,80)}=1.51, \mathrm{p}=0.23$, time, $\left.\mathrm{F}_{(2,80)}=2.41, \mathrm{p}=0.10\right)$.

272

273 The total time spent on self-maintenance activities increased over time, irrespectively of the

274

275

276

277

278

279

280

281

282

283

284

285

286

treatment (time, $\mathrm{F}_{(2,80)}=20.35, \mathrm{p}<0.0001$; day 0: $56.53 \pm 9.54 \mathrm{sec}$, day 15: $139.51 \pm 17.79 \mathrm{sec}$, day 30: $190.89 \pm 18.02 \mathrm{sec}$; time $\mathrm{x}$ treatment, $\mathrm{F}_{(4,80)}=0.99, \mathrm{p}=0.42$ ). Although birds did not differ in the duration of self- maintenance activities on day 0 (all $p>0.38$ ), there was an effect of treatment $\left(\mathrm{F}_{(2,80)}=4.49, \mathrm{p}=0.01 ; \mathrm{C}: 88.07 \pm 8.79 \mathrm{sec}\right.$, Caro: $163.06 \pm 23.12 \mathrm{sec}$, Chol: $\left.137.33 \pm 16.57 \mathrm{sec}\right)$, as overall, Caro birds spent more time than $\mathrm{C}$ birds in performing this activity $(74.99 \pm 25.46$ $[23.54,126.44])$, while any difference emerged between Chol- and C-males (49.26 \pm 25.03 [$1.32,99.85])$ or Caro- and Chol-males $(25.73 \pm 25.03[-24.86,76.31])$.

\section{Discussion}

Our study showed that male zebra finches exposed to a decreasing short photoperiod downregulated both their song activity and $\mathrm{T}$ level. This decreased song activity was not observed in males that received extra lutein or cholesterol, with males of both groups maintaining a constant song activity compared to the pre-treatment condition, although $\mathrm{T}$ levels were decreasing. As 
287 expected, in the treated birds circulating $\mathrm{T}$ decreased with the decreasing photoperiod but it was 288 unrelated to undirected song. Overall, the results show for the first time that zebra finch song is 289 influenced by food quality independently from caloric content.

290 Our results showed that birds eating ab libitum food but without any dietary enrichment 291 decrease their song activity in parallel with the decrease of circulating testosterone, but birds 292 treated with lutein or cholesterol did not. Generally, the reproductive state of an individual and 293 the associated hormonal profiles are important for the expression of birdsong. In several species 294 the neural system of birdsong is modulated by T (Nottebohm, 2005), but undirected song can be unrelated to reproduction and be T-independent (Bernard and Ball 1997; Eens 1997; Pinxten et al. 2002; Riters et al. 2002). For example, male European starlings perform undirected song yearround, including periods when T is very low (Eens 1997; Pinxten et al. 2002; Casagrande et al. 2014). This does not preclude that undirected song can be regulated by $\mathrm{T}$ in certain contexts. For example, starlings treated with exogenous $\mathrm{T}$ outside of the breeding season sing more frequently than non-treated individuals (Van Hout et al., 2011), indicating that T modulates this complex 301 signal.

In our study, control birds decreased their song activity with decreasing circulating $\mathrm{T}$ but they never ceased singing, even when the levels of this hormone were very low. One possibility is that the low levels of $\mathrm{T}$ measured on day 30 were sufficient to ensure the activation of the neuronal patterns involved in song performance (Pröve 1974). Similar to our results, Perfito and colleagues (2008) found that males kept under a short photoperiod with regressed gonads, low levels of luteinizing hormone, and full access to food sang more than birds exposed to a long photoperiod and fully activated reproductive state, indicating that food access, more than reproductive state, determines song activity in this species. In our study, males were not acoustically isolated from each other. We used this protocol because this species is highly gregarious and since they could not interact physically with each other, acoustic contact allowed them to continue to interact socially, which is important in this species. Nevertheless, we are confident that housing conditions did not affect the results in a significant way, since we have been able to detect between-group differences. We consider it unlikely that the positive effect of our dietary treatments was mediated by an increase in energy uptake as both nutrients are calorie-free, which is supported by the absence of an effect on body mass in our experiment. We 
318 birds and that the upregulation of singing activity paralleled this, as was also suggested in a

319 recent review on the relationship between birdsong and oxidative stress (Casagrande et al. 2016).

320 It has been previously observed that a lutein-rich diet affects the concentration of reactive

321 oxygen metabolites and increase the undirected song rate of male starlings (Casagrande et al.

322 2014) kept in outdoor aviaries and exposed to a short and decreasing photoperiod identical to the

323 artificially one created in the present study. In line with this is another study on the same species

324 showing that male song can convey information about the oxidative status of the individual

325 (Costantini et al., 2015). In the present study we could not determine the oxidative status of

326 birds, because the small size of the species did not allow us to collect enough blood volume to

327 assess both hormone concentrations and oxidative status. In contrast to the results obtained in

328 male starlings, where the dietary effect on song expression was already present after one week,

329 the effect in zebra finches was present only after one month. This difference in timing could be

330 due to differences in the housing conditions between the two studies, which were in large

331 outdoor aviaries for starlings and in individual indoor cages for zebra finches. Starlings had been

332 exposed to the lutein treatment in winter, when the ambient temperature was very low and when

333 an amelioration of their condition with the consumption of antioxidants would have a greater

334 impact in comparison with the situation of a constant environmental temperature of $20{ }^{\circ} \mathrm{C}$, as

335 was the case for zebra finches. Indeed, we observed an increase of oxidative damage during the

336 experiment in starlings, supporting this possibility. However, additional studies are needed to

337 further support this explanation.

338

339

340

\section{Conclusions}

None of the behaviors measured during the present study, except song activity, were significantly affected by the treatments, showing that birdsong is more sensitive to an improvement of the nutritional or physiological conditions than are other behavioral traits

344 (Cotton et al., 2004; Johnstone et al., 2009). Our data here suggest that the condition of the signaler, here related to the physiological condition of the individual (sensu Hill 2011), can be affected by the quality of the environment and in particular the nutritional value of food ingested, and that song activity can therefore potentially deliver information about the quality of the territory or about the foraging skills of the signaler. It has been demonstrated that singing activity 
349 is very sensitive to food availability (e.g. Ritschard and Brumm, 2012), but studies showing the 350 effect of food quality independent of caloric content are only starting to emerge (Van Hout et al. 351 2011, Casagrande et al. 2014). This is particularly important for species that sing year round, for 352 which seasonal changes in food quality can be a potential limiting factor in their singing

353 performance. For example, carotenoids are produced mostly by photosynthetic organisms that 354 usually show marked fluctuations between vegetative and non-vegetative phases. The 355 availability of micronutrients like carotenoids can indeed significantly fluctuate during time and 356 space (Eeva et al., 2011). Eeva and colleagues found that in deciduous or mixed forests eggs laid 357 by the pied flycatchers Ficedula hypoleuca before leaf unfolding of birch had a lower carotenoid 358 concentration than the ones laid later, indicating an important temporal pattern in dietary 359 carotenoid availability. Different biomes can extensively differ in their capacity to provide 360 carotenoids (Eeva et al. 2011). Thus, it is not unlikely to assume that singing activity can be 361 affected by all these environmental parameters and future studies should address this possibility 362 in free-living birds.

363

364

365 version of the manuscript and for providing highly valuable comments. We thank Peter Scheys and Geert Eens for their assistance in many steps of the experiment and for solving several logistic issues. We thank Pralle Kriengwatana and one anonymous reviewer for raising very 369 constructive comments in the revision process, contributing to improve the quality of the 370 manuscript. 
References

1. Allen, P.C., Wong, H.Y.C., 1993. Effect of atherogenic diet on chicken plasma lipids and lipoproteins. Poult Sci 72, 1673-1678.

2. Alonso-Alvarez, C., Bertrand, S., Devevey, G., Gaillard, M., Prost, J., Faivre, B., Sorci, G., 2004. An experimental test of the dose-dependent effect of carotenoids and immune activation on sexual signals and antioxidant activity. Am. Nat. 164, 651-9. doi:10.1086/424971

3. Bentley, G.E., Spar, B.D., MacDougall-Shackleton, S.A., Hahn, T.P., Ball, G.F., 2000. Photoperiodic regulation of the reproductive axis in male zebra finches, Taeniopygia guttata. Gen. Comp. Endocrinol. 117, 449-455. doi:10.1006/gcen.1999.7430

4. Bernard, D.J., Ball, G.F., 1997. Photoperiodic condition modulates the effects of testosterone on song control nuclei volumes in male European starlings. Gen. Comp. Endocrinol. 105, 276-83. doi:10.1006/gcen.1996.6829

5. Blount, J.D., 2004. Carotenoids and life-history evolution in animals. Arch. Biochem. Biophys. 430, 10-5. doi:10.1016/j.abb.2004.03.039

6. Blount, J.D., Metcalf, N.B., Birkhead, R., Surai, P.F., 2003. Carotenoid modulation of immune function and sexual attractiveness in zebra finches. Science 300, 125-127.

7. Brown, A.J., Galea, A.M., 2010. Cholesterol as an evolutionary response to living with oxygen. Evolution 64, 2179-83. doi:10.1111/j.1558-5646.2010.01011.x

8. Casagrande, S., Dijkstra, C., Tagliavini, J., Goerlich, V.C., Groothuis, T.G.G., 2011. Differential effects of testosterone, dihydrotestosterone and estradiol on carotenoid deposition in an avian sexually selected signal. J. Comp. Physiol. A. Neuroethol. Sens. Neural. Behav. Physiol. 197, 1-13. doi:10.1007/s00359-010-0579-4

9. Casagrande, S., Pinxten, R., Zaid, E., Eens, M., 2014. Carotenoids, birdsong and oxidative status: administration of dietary lutein is associated with an increase in song rate and circulating antioxidants (albumin and cholesterol) and a decrease in oxidative damage. PLoS One 9, e115899. doi:10.1371/journal.pone.0115899

10. Casagrande, S., Pinxten, R., Zaid, E., Eens, M., 2015. Birds receiving extra carotenoids keep singing during the sickness phase induced by inflammation. Behav. Ecol. Sociobiol. 69, 1029-1037. doi:10.1007/s00265-015-1916-y

11. Catchpole, C. K. \& Slater, P.J.B. 2008. Bird Song: Biological themes and variations, 2nd ed. Cambridge University Press, Cambridge U.K.

12. Chew, B.P., Park, J.S., 2004. Functions and actions of retinoids and carotenoids: building on the vision of James Allen Olson carotenoid action on the immune response. J. Nutr. 134, 257S-261S.

13. Costantini, D., Casagrande, S., Casasole, G., AbdElgawad, H., Asard, H., Pinxten, R., Eens, M., 2015. Immunization reduces vocal communication but does not increase oxidative stress in a songbird species. Behav. Ecol. Sociobiol. 69, 829-839. doi:10.1007/s00265-015-1899-8

14. Cotton, S., Fowler, K., Pomiankowski, A., 2004. Do sexual ornaments demonstrate heightened condition-dependent expression as predicted by the handicap hypothesis? Proc. R. Soc. London Biol. Sci. 271, 771-783.

15. Davies, N.B., Lundberg, A., 1984. Food distribution and a valriable mating system in the dunnock, Prunella modularis. J. Anim. Ecol. 53, 895-912.

16. Duffy, D.L., Ball, G.F., 2002. Song predicts immunocompetence in male European starlings (Sturnus vulgaris). Proc. R. Soc. London. Biol. Sci. 269, 847-852. doi:10.1098/rspb.2002.1956

17. Dunn, a. M., Zann, R., 1996. Undirected Song in wild zebra finch flocks: Contexts and effects of mate removal. Ethology 102, 529-539. doi:10.1111/j.1439-0310.1996.tb01145.x 
419

420

421

422

423

424

425

426

427

428

429

430

431

432

433

434

435

436

437

438

439

440

441

442

443

444

445

446

447

448

449

450

451

452

453

454

455

456

457

458

459

460

461

462

463

464

465

18. Dunn, A.M., Zann, R.A., 1997. Effects of pair bond and presence of conspecifics on singing in captive zebra finches. Behaviour 134, 127-142.

19. Eens, M., 1997. Understanding the complex song of the European starling: An integrated ethological approach. Adv. Study Behav. 26, 355-434.

20. Eeva, T., Ruuskanen, S., Salminen, J.-P., Belskii, E., Järvinen, A., Kerimov, A., Korpimäki, E., Krams, I., Moreno, J., Morosinotto, C., Mänd, R., Orell, M., Qvarnström, A., Siitari, H., Slater, F.M., Tilgar, V., Visser, M.E., Winkel, W., Zang, H., Laaksonen, T., 2011. Geographical trends in the yolk carotenoid composition of the pied flycatcher (Ficedula hypoleuca). Oecologia 165, 277-87. doi:10.1007/s00442-010-1772-4

21. Franz, M., Goller, F., 2003. Respiratory patterns and oxygen consumption in singing zebra finches. J. Exp. Biol. 206, 967-978. doi:10.1242/jeb.00196

22. Garamszegi, L.Z., Møller, A.P., Erritzøe, J., 2003. The evolution of immune defense and song complexity in birds. Evolution 57, 905-12.

23. Geberzahn, N., Gahr, M., 2011. Undirected (solitary) birdsong in female and male bluecapped cordon-bleus (Uraeginthus cyanocephalus) and its endocrine correlates. PLoS One 6, e26485. doi:10.1371/journal.pone.0026485

24. Gil, D., Gahr, M., 2002. The honesty of bird song: multiple constraints for multiple traits. Trends Ecol. Evol. 17, 133-141. doi:10.1016/S0169-5347(02)02410-2

25. Hasselquist, D., Bensch, S., 2008. Daily energy expenditure of singing great reed warblers Acrocephalus arundinaceus. J. Avian Biol. 39, 384-388. doi:10.1111/j.2008.09088857.04427.x

26. Hill, G.E., 2011. Condition-dependent traits as signals of the functionality of vital cellular processes. Ecol. Lett. 14, 625-34. doi:10.1111/j.1461-0248.2011.01622.x

27. Hill, G. E., Johnson, J.D., 2012. The vitamin A-redox hypothesis: a biochemical basis for honest signaling via carotenoid pigmentation. Am. Nat. 180, E127-50. 596 doi:10.1086/667861

28. Jarvis, E.D., Scharff, C., Grossman, M.R., Ramos, J.A., Nottebohm, F., 1998. For whom the bird sings: Context-dependent gene expression. Neuron 21, 775-788. doi:10.1016/S08966273(00)80594-2

29. Jesse, F., Riebel, K., 2012. Social facilitation of male song by male and female conspecifics in the zebra finch, Taeniopygia guttata. Behav. Processes 91, 262-6. doi:10.1016/j.beproc.2012.09.006

30. Johnstone, R. a, Rands, S., Evans, M.R., 2009. Sexual selection and condition-dependence. J. Evol. Biol. 22, 2387-94. doi:10.1111/j.1420-9101.2009.01822.x

31. Holveck, M.J., Riebel, K., 2007. Preferred songs predict preferred males: consistency and repeatability of zebra finch females across three test contexts. Anim. Behav. 74, 297-309. doi:10.1016/j.anbehav.2006.08.016

32. Kazuyoshi, T., Takeshi, Y., 1995. Avian neurosteroids. I. Pregnenolone biosynthesis in the quail brain. Brain Res. 678, 1-9. doi:http://dx.doi.org/10.1016/0006-8993(95)00116-8

33. Lampe, H.M., Espmark, Y.O., 2002. Mate choice in pied flycatchers Ficedula hypoleuca: can females use song to find high-quality males and territories? Ibis 145, E24-E33. doi:10.1046/j.1474-919X.2003.00144.x

34. Lemon, W.C., 1991. Fitness consequences of foraging behaviour in the zebra finch. Nature 352:153-155.

35. Lopes, P.C., Wingfield, J.C., Bentley, G.E., 2012. Lipopolysaccharide injection induces rapid decrease of hypothalamic GnRH mRNA and peptide, but does not affect GnIH in zebra finches. Horm. Behav. 62, 173-179. doi:10.1016/j.yhbeh.2012.06.007 
36. Lynn, S.E., Stamplis, T.B., Barrington, W.T., Weida, N., Hudak, C., 2010. Food, stress, and reproduction: short-term fasting alters endocrine physiology and reproductive behavior in the zebra finch. Horm. Behav. 58, 214-22. doi:10.1016/j.yhbeh.2010.03.015

37. McGraw, K.J., Ardia, D.R., 2003. Carotenoids, immunocompetence, and the information content of sexual colors: an experimental test. Am. Nat. 162, 704-12. doi:10.1086/378904

38. McGraw, K.J., Parker, R.S., 2006. A novel lipoprotein-mediated mechanism controlling sexual attractiveness in a colorful songbird. Physiol. Behav. 87, 103-8. doi:10.1016/j.physbeh.2005.09.001

39. Møller, a P., Henry, P.Y., Erritzøe, J., 2000. The evolution of song repertoires and immune defence in birds. Proc. Biol. Sci. 267, 165-9. doi:10.1098/rspb.2000.0982

40. Murphy, R.C., Johnson, K.M., 2008. Cholesterol, reactive oxygen species, and the formation of biologically active mediators. J. Biol. Chem. 283, 15521-5. doi:10.1074/jbc.R700049200

41. Nottebohm, F., 2005. The neural basis of birdsong. PLoS Biol. 3, 0759-0761. doi:10.1371/journal.pbio.0030164

42. Nowicki, S., Searcy, W., 2004. Song function and the evolution of female preferences: why birds sing, why brains matter. Ann. N. Y. Acad. Sci. 1016, 704-23. doi:10.1196/annals.1298.012

43. Ophir, a G., Schrader, S.B., Gillooly, J.F., 2010. Energetic cost of calling: general constraints and species-specific differences. J. Evol. Biol. 23, 1564-9. doi:10.1111/j.14209101.2010.02005.x

44. Pérez-Rodríguez, L. 2009. Carotenoids in evolutionary ecology: re-evaluating the antioxidant role. BioEssays 31, 1116-26. doi:10.1002/bies.200900070

45. Perfito, N., Bentley, G., Hau, M., 2006. Tonic activation of brain GnRH immunoreactivity despite reduction of peripheral reproductive parameters in opportunistically breeding zebra finches. Brain. Behav. Evol. 67, 123-34. doi:10.1159/000090977

46. Perfito, N., Kwong, J.M.Y., Bentley, G.E., Hau, M., 2008. Cue hierarchies and testicular development: is food a more potent stimulus than day length in an opportunistic breeder (Taeniopygia g. guttata)? Horm. Behav. 53, 567-72. doi:10.1016/j.yhbeh.2008.01.002

47. Perfito, N., Zann, R. a., Hau, M., Bentley, G.E., 2015. Seasonal-like variation in song control system volume of wild zebra finches. J. Exp. Zool. Part A Ecol. Genet. Physiol. 323, 586591. doi:10.1002/jez.1956

48. Pinxten, R., De Ridder, E., Balthazart, J., Eens, M., 2002. Context-dependent effects of castration and testosterone treatment on song in male European starlings. Horm. Behav. 42, 307-318. doi:10.1006/hbeh.2002.1824

49. Prior, N.H., Soma, K.K., 2015. Neuroendocrine regulation of long-term pair maintenance in the monogamous zebra finch. Horm. Behav. doi:10.1016/j.yhbeh.2015.04.014

50. Pröve, E., 1974. Der Einfluss von Kastration und Testosteronsubstitution auf das Sexualverhalten männlicher Zebrafinken (Taeniopygia guttata castanotis Gould). J Ornithol $115,338-347$.

51. Pröve, E., Immelmann, K., 1982. Behavioral and hormonal responses of male zebra finches to antiandrogens. Horm. Behav. 16, 121-31.

52. Riebel, K., 2009. Song and Female Mate Choice in Zebra Finches : A Review. Adv. Study Behav. 40, 197-238. doi:10.1016/S0065-3454(09)40006-8

53. Riters, L. V, 2011. Pleasure seeking and birdsong. Neurosci. Biobehav. Rev. 35, 1837-45. doi:10.1016/j.neubiorev.2010.12.017

54. Riters, L. V, Eens, M., Pinxten, R., Ball, G.F., 2002. Seasonal changes in the densities of alfa2 - noradrenergic receptors are inversely related to changes in testosterone and the volumes of song control nuclei in male European starlings. J. Comp. Neurol. 444, 63-74. doi:10.1002/cne.10131 
515

55. Ritschard, M.H., Brumm, H., 2012. Zebra finch song reflects current food availability. Evol. Ecol. 26, 801-812. doi:10.1007/s10682-011-9541-3

56. Searcy, W.A., Yasukawa, K., 1996. Song and female choice. In: Ecology and evolution of acoustic communication in birds. Comstock Publishing Associates, Ithaca.

57. Smith, L.L., 1991. Another cholesterol hypothesis: cholesterol as antioxidant. Free Radic. Biol. Med. 11, 47-61.

58. Sossinka, R., Boehner, J., 1980. Song types in the zebra finch Poephila futtata castanotis. J Comp. Ethol. 53, 123-132.

59. Svensson, P.A., Wong, B.B.M., 2011. Carotenoid-based signals in behavioural ecology: a review. Behaviour 148, 131-189. doi:10.1163/000579510X548673

60. Tomaszycki, M.L., Adkins-Regan, E., 2005. Experimental alteration of male song quality and output affects female mate choice and pair bond formation in zebra finches. Anim. Behav. 70, 785-794. doi:10.1016/j.anbehav.2005.01.010

61. Tregenza, T., Simmons, L.W., Wedell, N., Zuk, M., 2006. Female preference for male courtship song and its role as a signal of immune function and condition. Anim. Behav. 72, 809-818. doi:10.1016/j.anbehav.2006.01.019

62. Van Hout, A.J.-M., Eens, M., Balthazart, J., Pinxten, R., 2009. Complex modulation of singing behavior by testosterone in an open-ended learner, the European starling. Horm. Behav. 56, 564-73. doi:10.1016/j.yhbeh.2009.09.010

63. Van Hout, A.J.M., Eens, M., Pinxten, R., 2011. Carotenoid supplementation positively affects the expression of a non-visual sexual signal. PLoS One 6, e16326. doi:10.1371/journal.pone.0016326

64. Van Hout, A.J.-M., Pinxten, R., Geens, A., Eens, M., 2012. Non-breeding song rate reflects nutritional condition rather than body condition. PLoS One 7, e36547. doi:10.1371/journal.pone.0036547

65. Ward S., 2004. Singing is not energetically demanding for pied flycatchers, Ficedula hypoleuca. Behav Ecol 15, 477-484. doi:10.1093/beheco/arh038

66. Vinkler, M., Albrecht, T., 2010. Carotenoid maintenance handicap and the physiology of carotenoid-based signalisation of health. Naturwissenschaften 97, 19-28. doi:10.1007/s00114-009-0595-9

67. Von Schantz, T., Bensch, S., Hasselquist, D., Wittzell, H., 1999. Good genes, oxidative stress and condition-dependent sexual signals. Proc. R. Soc. London Bio. Sci. 266, 1-12.

68. Walters, M.J., Collado, D., Harding, C.F., 1991. Oestrogenic modulation of singing in male zebra finches: differential effects on directed and undirected songs. Anim. Behav. 42, 445452.

69. Ward, S., 2004. Singing is not energetically demanding for pied flycatchers, Ficedula hypoleuca. Behav. Ecol. 15, 477-484. doi:10.1093/beheco/arh038

70. Wilson, A.J., Nussey, D.H., 2010. What is individual quality? An evolutionary perspective. Trends Ecol. Evol. 25, 207-214. doi:10.1016/j.tree.2009.10.002

71. Zann, R., 1996. The Zebra finch: a synthesis of field and laboratory studies. Oxford University Press, Oxford.

72. Zann, R.A., Morton, S.R., Jones, K.R., Burley, N.T., 1995. The timing of breeding in zebra finches in relation to rain- fall. Emu 98, 208-222.

73. Zollinger, S.A., Goller, F., Brumm, H., 2011. Metabolic and respiratory costs of increasing song amplitude in zebra finches. PLoS One 6, e23198. doi:10.1371/journal.pone.0023198. 
561 Figure 1. Timing of the experiment

562

\begin{tabular}{|lrr|}
\hline $9 h 22 m$ & $8 h 36 m$ & $8 h 04 m$ \\
\hline
\end{tabular}

Blood and biometric
sampling
Start of diet
treatment (after first
sampling)


564

565 Figure 2. Variation of time spent singing (a), testosterone (b) and body mass (c) in the three 566 treatments: Controls (open circle), Carotenoids (black circle) and Cholesterols (grey circle).

567 Different letters refer to post-hoc within-group significant differences between days in relation to 568 day 0 (Controls: small case, Carotenoids: uppercase, Cholesterols: italic). P values refer to 569 significant difference of post-hoc comparisons between dietary groups, within the same day. 570 Dots are mean values and bars s.e. 


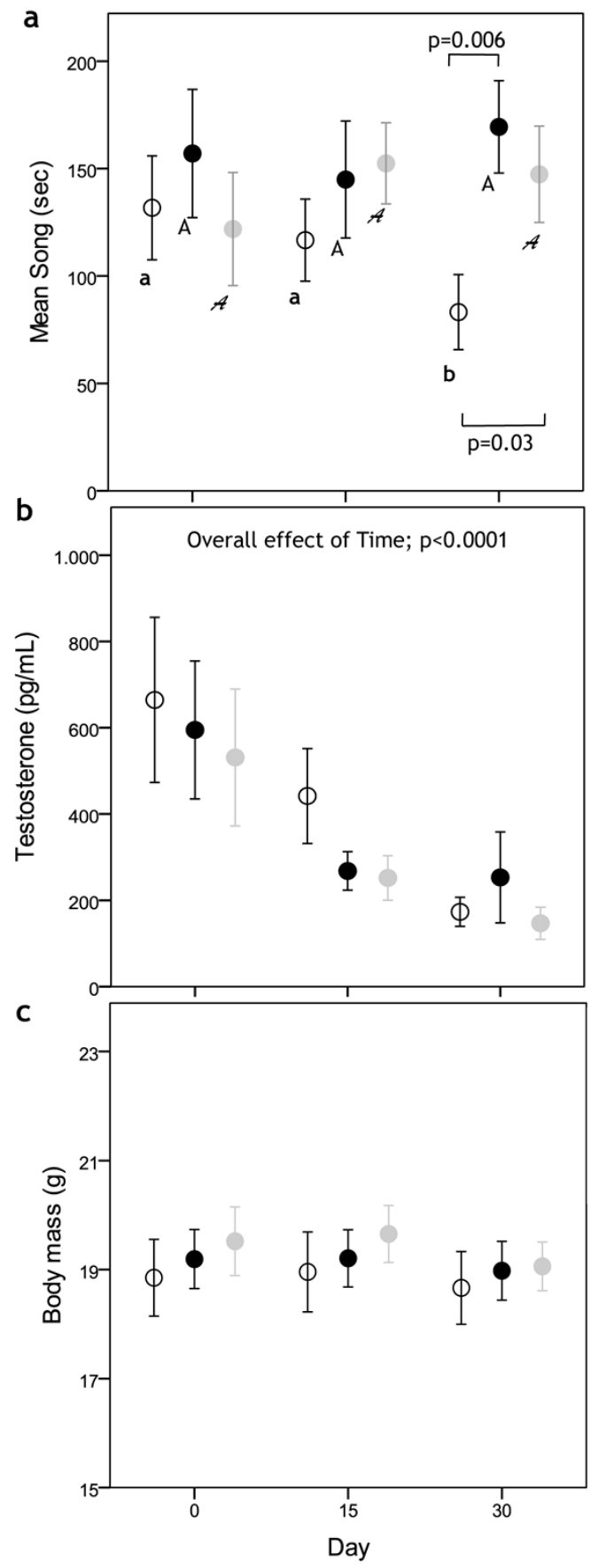

